\title{
Methods of calculating landslide volume using remote sensing data
}

\author{
Maira Razakova ${ }^{1}$, Alexandr Kuzmin ${ }^{1}$, Igor Fedorov ${ }^{1}$, Rustam Yergaliev ${ }^{1}$ and Zharas \\ Ainakulov ${ }^{2 *}$ \\ ${ }^{1}$ JSC "National Center for Space Research and Technology", 050010, Almaty, Kazakhstan \\ 2 Al-Farabi Kazakh National University, 050040, Almaty, Kazakhstan
}

\begin{abstract}
The paper considers the issues of calculating the volume of the landslide from remote sensing data. The main methods of obtaining information during research are field observations. The most important results of field studies are quantitative estimates, such as the volume of the embankment resulting from a landslide, morphometric indicators, etc. The study of a remote and remote object was carried out by remote methods using aerial photographs in the Ile Alatau foothills at 1,600 meters above sea level. The obtained materials from the mudflow survey will be useful in developing solutions to mitigate the effects of disasters and in the design of measures for engineering protection from landslides.
\end{abstract}

\section{Introduction}

The consequences of the mudflow can be catastrophic - the destruction of roads, industrial facilities and settlements. The obtained materials for determining the volume of mudflow will be useful in the development of solutions for the elimination of the consequences of disasters and in the design of measures for engineering protection from mudflows.

The aim of this work was to assess the environmental impacts of mudflow according to aerial photographs.

The object of the study was the events of May 14, 2018, when in the Aksai gorge due to heavy rainfall in the form of rain, a mudflow of 800 cubic meters occurred along the Kyzylzhar river (a tributary of the Aksai river) [1].

In practice, mudflow characteristics are calculated according to the requirements of [2$3]$. One of the main parameters of mudflow, affecting the choice of measures, is the volume of mudflow $\mathrm{V}_{\mathrm{c}}$ in $\mathrm{m}^{3}$ determined by the formula:

$$
V_{c}=V_{k}+V_{t}+V_{p}+V_{p w}
$$

where $\mathrm{V}_{\mathrm{k}}$ is the volume of coarse material deposited in the removal cone, $\mathrm{m}^{3} ; \mathrm{V}_{\mathrm{t}}$ is the volume of coarse material deposited in the transit zone, $\mathrm{m}^{3} ; \mathrm{V}_{\mathrm{p}}$ is the volume of finely

*Corresponding author: jaras1987@mail.ru 
dispersed material carried out by the mud flood beyond the boundaries of the mud flow, $\mathrm{m}^{3}$; $\mathrm{V}_{\mathrm{pw}}$ is the volume of the water after-debris flood, $\mathrm{m}^{3}$.

The volume of mudflow of any type in the presence of observations of mudflows can be approximately determined by the formula:

$$
V_{c}=0,5 \cdot Q_{\max } \cdot T
$$

where $\mathrm{Q}_{\max }$ is the maximum mudflow rate, $\mathrm{m}^{3} / \mathrm{s} ; \mathrm{T}$ - duration of mudflow, c.

To identify the general patterns of the emergence and development of catastrophic mudflows and landslides, a comprehensive detailed study of the entire territory covered by the process is necessary.

The main methods for obtaining information during research are field observations. The most important results of field studies are quantitative estimates, such as the volumes of mudflows, morphometric indicators, etc. Studying a remote and inaccessible object was carried out by remote sensing methods using aerial photographs in the foothills of Ile Alatau at an altitude of 1600 meters above sea level. The prevailing volumes of mudflows are usually formed due to moraine and alluvial-proluvial accumulations [4].

In this paper, the authors proposed an alternative method for calculating $V_{c}, V_{k}, V_{t}, V_{p}$ based on the construction of a digital terrain model (DTM) based on aerial photography.

Aerial survey of the study area was carried out by an unmanned aerial vehicle (UAV), hexacopter [5-6]. Field topographic and geodetic works were preliminarily carried out for the placement of identification marks on the terrain, on which planned high-altitude measurements were made. Areas of accumulation of mudflow deposits are identified, heterogeneity of mudflow structure is classified, in our case, mud-stone mudflow spread over several kilometers prevailed, a microrelief of the mudflow channel surface was built. Mudflow deposits were insignificant in the form of mud-stone mass along the river bed. On the territory of the mudflow, the bulk of the mudflow occurred in a landslide. The calculated volume of the embankment formed as a result of the landslide occurred, according to the digital terrain model, coincided with ground-based measurements.

To identify the structural and topographic features of the landslide processes, we used photogrammetry methods, geoinformation technologies for constructing elevation contours, slopes, volume calculations, etc.

A lot of work has been done on the information and analytical support of such a natural phenomenon as a landslide.

\section{Research methods}

One of the stages of the recognition and fixation of a landslide was space monitoring. In order to study the cause and effect parameters of the landslide occurrence process that are characteristic of a given area, first of all, remote sensing (RS) data were used. At the initial stage, remote sensing was analyzed to detect changes in the earth's surface, or characteristic signs of landslide processes, such as soil slipping, soil exposure [7].

A general overview of the terrain was made and a survey was made with the UAV camera Sony NEX-5N of the site where the mudflow passed. The survey was carried out from a height of $200 \mathrm{~m}$ above the level of the surface (soil). The classification of altitude data is based on the ranking of colors from blue to red. The high spatial resolution of the DTM allows us to talk about the microrelief - local relief forms such as embankments, sediments, etc. are distinguished. By traditional methods for calculating the characteristics of mudstone mudflows of glacial origin, the mudflow channel (from the largest glacier to the settlement section) is divided into $10-20$ characteristic sections so that about half of 
them are at angles over $6^{\circ}$. The length of the calculation section can vary from 300 to 2000 $\mathrm{m}$. The calculation is made sequentially in sections [3].

\section{Results}

Based on the survey materials, an orthophotomap was constructed in the visible wavelength spectrum and a DTM was obtained. The spatial resolution of the orthomosaic is $5 \mathrm{~cm}$ and the DTM is $12 \mathrm{~cm}$ (Fig. 1).

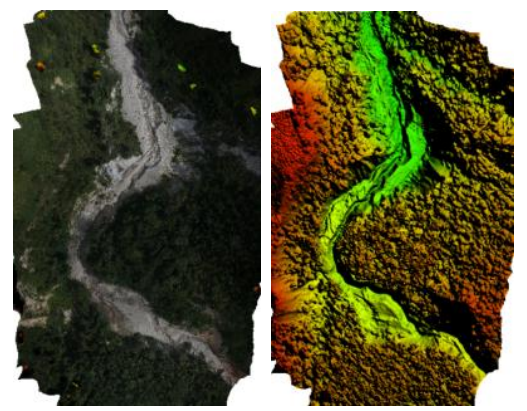

Fig. 1. Orthophotomap and DTM in the color palette according to the data from the UAV survey, the territory where the landslide occurred on May 14, 2018.

In the place where the landslide occurred, an embankment formed, the contour is highlighted in red in Fig. 2.

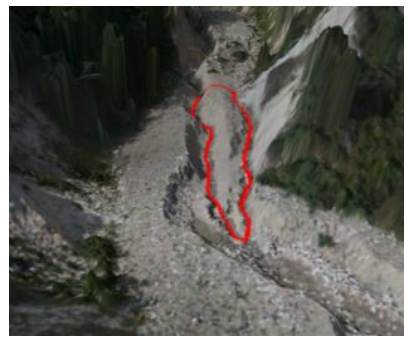

Fig. 2. 3D image of a DTM fragment obtained from aerial photography.

To calculate the volume of the embankment, a surface was constructed from the ground points of the contour of the embankment and the height surface of the embankment was selected (Fig. 3).
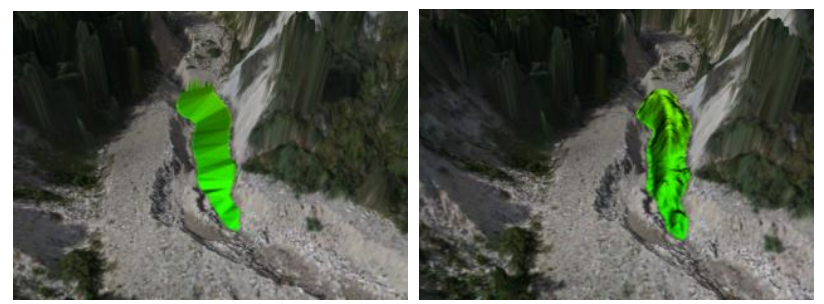

Fig. 3. 3D image of a DTM fragment, with a surface along the ground points of the embankment contour and a height file with the selected embankment surface. 
As a result, a volumetric representation of the body of the embankment was obtained. (Fig. 4).

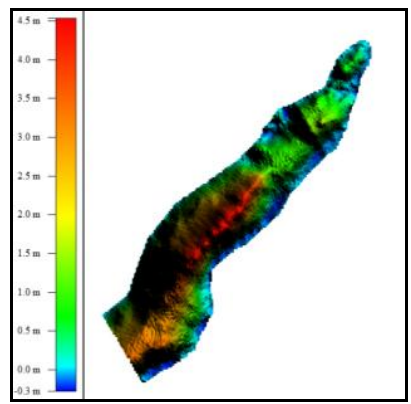

Fig. 4. Height file for the selected mound surface.

The volume of the embankment was calculated by geographic information methods, summing up the pixel-by-pixel components of a three-dimensional figure and amounted to $713.5 \mathrm{~m} 3$ [8]. The calculated volume according to aerial survey and ground-based measurements [9] coincided.

\section{Conclusion}

Since mudflow landslides threaten nearby settlements, it is necessary to carry out their constant monitoring in seasonally wet periods. Using aerial photography with UAVs, one can observe the dynamics of the movement and spread of mudflow landslides. A detailed survey makes it possible in the future to issue recommendations for measures to strengthen the places where mudflows pass, to prevent their harmful effects on the places of population living. Assess damage and devastating effects on human settlements. (In mid2018, all the structures of the nearby dacha village Koklaisay were digitized and entered into the GIS).

\section{References}

1. https://tengrinews.kz/events/sel-soshel-bliz-almatyi-344188/

2. SP 33 - 101 - 2003. Determination of the main calculated hydrological characteristics. Gosstroy of Russia. - M .: FSUE TsPP. - 73 s (2004)

3. $\mathrm{P}-814-84$. Recommendations for the design of anti-mudflow protective structures. Hydroproject. - M .: Hydroproject. - 112 s (1985)

4. A.R. Medeu, V.P. Blagoveshchensky, T.A. Baimoldaev, T.L. Kirenskaya, B.S. Stepanov Mudflows of South-East Kazakhstan. - Almaty: Institute of Geography. T. 2. Part 2. The basics of monitoring in Ile Alatau. - 288 s (2018)

5. Zh.Zh. Ainakulov, N.G. Makarenko, T.T. Paltashev. Experience of modeling mining landscapes by using methods of intelligent monitoring. The journal "Current problems in remote sensing of the Earth from space". -Volume 15. -№7. - P. 43-50 (2018)

6. Zh.Zh. Ainakulov, N.G. Makarenko, T.T. Paltashev. Intelligent Monitoring on the Basis of a UAV for Assessing and Predicting the Condition of Objects with Complex Relief. International Journal of Applied Mathematics and Informatics. Volume 13 (2019)

7. M.G. Razakova, A.G. Kuzmin, Zh.Zh. Ainakulov, E.E. Aidarkhanov, I.O. Fedorov, R.K. Ergaliev. Methodical aspects of using aerospace data for monitoring hazardous 
natural phenomena // Abstracts of International Symposium on Water and Land Resources in Central Asia. October 9 - 11, 2018. Almaty, Kazakhstan, 2018 .-- 1 p. (Organizers: GFZ - German Research Center for Geosciences, German-Kazakh University, University of Würzburg) (2018)

8. V.F. Kutyrev. Volume calculation using MapINFO Professional. Moscow. Geoprofi number 3. 2008. S.53-54 (2008)

9. I.M. Vaskov. On the methodology and methods of studying glacial mudflows and their genesis. // Debris flows: disasters, risk, forecast, protection. Materials of the IV International Conference Russia, Irkutsk - pos. Arshan (Republic of Buryatia) September 6-10, 2016 S. 28-36 (2016) 